\title{
Single chamber atrial pacing: an underused and cost-effective pacing modality in sinus node disease
}

\author{
K W Clarke, D T Connelly, R G Charles
}

\begin{abstract}
Objective-To determine the safety and cost effectiveness of single chamber atrial pacing in patients with sinus node disease. Design-Retrospective follow up study. Setting-Tertiary referral centre. Patients-81 patients with single chamber atrial pacemakers implanted between 1992 and 1996.

Main outcome measures-The development of high grade atrioventricular block resulting in a further pacemaker procedure. The cost savings of changing our current pacing practice to conform with British Pacing and Electrophysiology Group guidelines.

Results-During the follow up period, four patients $(5.8 \%)$ required a further procedure to upgrade their atrial pacemaker to a dual chamber system owing to the development of high grade atrioventricular block. In 1995 and 1996, 343 pacemakers were implanted in patients with sinus node disease; 19 (5.5\%) received single chamber atrial pacemakers and 271 $(79 \%)$ dual chamber pacemakers. If the current pacing practice was changed so that all patients received single chamber atrial pacemakers, with revision for symptomatic atrioventricular block, savings in excess of $£ 206000$ would have been made in the two year period.

Conclusions-Atrial pacing in patients with sinus node disease is underused. The need for patients to undergo further procedures owing to the development of atrioventricular block is small and significant cost savings could be made by changing pacemaker practice.

(Heart 1998;80:387-389)
\end{abstract}

Keywords: sinus node disease; atrial pacing; cost effectiveness

Sinus node disease is a relatively common indication for the implantation of a permanent pacemaker. Figures from the British Pacing and Electrophysiology Group (BPEG) show that of the 12500 pacemakers implanted in the United Kingdom each year, approximately $25 \%$ are for sinus node disease with no evidence of associated atrioventricular block, ${ }^{1}$ and the recommended pacemaker prescription for these patients is atrial pacing with rate response if appropriate. ${ }^{1}$ A review of pacemaker prescriptions in the Cardiothoracic Centre in Liverpool showed an increase in physiological pacing modes in patients with sinus node disease between 1984 and $1994 .^{2}$ We currently implant approximately 175 permanent pacemakers each year in patients with sinus node disease. Of these, approximately $6 \%$ receive single chamber atrial pacemakers, $15 \%$ single chamber ventricular pacemakers, and $79 \%$ dual chamber pacemakers.

There is good evidence to support atrial based pacing rather than ventricular pacing in patients with sinus node disease, ${ }^{3-6}$ but there is the small risk of the subsequent development of high grade atrioventricular block, ${ }^{35} 5^{7-9}$ which would require a further pacemaker procedure in those patients without a ventricular pacing lead. To overcome these problems dual chamber pacing may seem an attractive option in patients with sinus node disease and indeed has been recommended by some cardiologists. ${ }^{10}$ Dual chamber pacing is more expensive than single chamber pacing, and while dual chamber pacing has been shown to be cost effective compared with ventricular pacing, ${ }^{11}$ there are no similar comparisons of cost effectiveness of single chamber atrial pacing with dual chamber pacing in patients with sinus node disease.

We decided to review our practice of pacemaker prescription in patients with sinus node disease to determine the rate of development of atrioventricular block and the number of revision procedures, and to estimate any cost savings that could be made by implanting atrial rather than dual chamber pacemakers where appropriate.

\section{Methods}

Data concerning pacemaker implants in the Cardiothoracic Centre, Liverpool, are stored on a computer database. From this database we were able to identify patients who had single chamber atrial pacemakers implanted between 1992 and 1996. We examined the case notes of these patients and from data recorded were able to establish the number of patients who developed symptomatic atrioventricular block and required a further procedure to upgrade their pacemaker system to a dual chamber system.

Table 1 Pacemaker prescriptions for patients with sinus node disease with no evidence of atrioventricular block 1995-96

\begin{tabular}{lc}
\hline & Number (\%) \\
\hline Atrial pacemakers & $19(5.5)$ \\
Dual chamber pacemakers & $271(79)$ \\
Ventricular pacemakers & $53(15.5)$ \\
Total & 343 \\
\hline
\end{tabular}


Table 2 Pacemaker upgrades from single chamber atrial pacing to dual chamber pacing

\begin{tabular}{lllll}
\hline $\begin{array}{l}\text { Age at } \\
\text { implant } \\
\text { (years) }\end{array}$ & $\begin{array}{l}\text { Months after } \\
\text { implant to } \\
\text { upgrade }\end{array}$ & Date of upgrade & Symptoms & ECG findings \\
\hline 82 & 20 & $29 / 09 / 96$ & $\begin{array}{l}\text { Blackouts } \\
\text { Syncope }\end{array}$ & $\begin{array}{l}\text { AV block } \\
\text { Prolonged PR interval Wenckebach rate } \\
120 \text { beats/min } \\
\text { Wenckebach rate } 70 \text { beats/min } \\
\text { (routine follow up) }\end{array}$ \\
56 & 102 & $10 / 07 / 96$ & None & $\begin{array}{c}\text { Symptomatic Wenckebach at } 100 \\
\text { beats/min }\end{array}$ \\
73 & 44 & $09 / 09 / 94$ & Dizzy & \\
\hline
\end{tabular}

Finally, we estimated the cost savings we would make by implanting atrial rather than dual chamber pacemakers, allowing for those patients who would require a second procedure.

\section{Results}

From our database we were able to identify 81 patients who had atrial pacemakers implanted between 1992 and 1996. Eight patients had died between 1993 and 1997 . We were able to retrieve and examine the case notes of 68 of the remaining 73 patients.

The breakdown of pacemaker prescriptions from our centre for patients with sinus node disease with no atrioventricular node disease for the years 1995 and 1996 is shown in table 1 .

PATIENT DEMOGRAPHY

The patients' age at implant ranged from 42 to 90 years (mean 71.8 , median 72 ); 24 patients $(35 \%)$ were aged 70 years or below; $44(65 \%)$ were female, $24(35 \%)$ were male.

FOLLOW UP

Patients were followed for up to 108 months (mean 29.5, median 25).

PRE-IMPLANT ELECTROCARDIOGRAM

The pre-implant electrocardiogram showed a normal PR interval and normal QRS duration in all but three patients: one was in atrial fibrillation at the time of implant but had previously been in normal sinus rhythm, one had bifascicular block, and one had first degree atrioventricular block.

WENCKEBACH RATE

The antegrade Wenckebach rate at implant was recorded in 35 patients $(51 \%)$. In each patient the rate was greater than 120 beats/min.

Table 3 Cost of our current pacing practice

\begin{tabular}{|c|c|c|c|}
\hline 1995-96 & Number & Cost & Total \\
\hline Atrial implants & 19 & $£ 2855$ & $£ 54815$ \\
\hline Dual chamber implants & 271 & $f^{3} 344$ & $£ 1041724$ \\
\hline $\begin{array}{l}\text { Cost of upgrading to dual } \\
\text { chamber pacemakers } \\
\text { Total }\end{array}$ & 3 & $£ 3844$ & $\begin{array}{r}£ 11532 \\
£ 1108071\end{array}$ \\
\hline
\end{tabular}

Table 4 Cost savings of changing our pacing practice to conform with BPEG recommendations

\begin{tabular}{|c|c|c|c|}
\hline $1995-96$ & Number & Cost & Total \\
\hline Atrial implants & 290 & $£ 2885$ & $£ 836650$ \\
\hline $\begin{array}{l}\text { Cost of upgrading atrial to } \\
\text { dual chamber pacemakers } \\
\text { Total cost }\end{array}$ & 17 & $£ 3864$ & $\begin{array}{r}£ 65484 \\
£ 901998\end{array}$ \\
\hline
\end{tabular}

REVISIONS

Fifteen patients $(22 \%)$ required revision procedures during the follow up period. Seven required atrial lead repositioning and one a generator change because of generator recall by the manufacturer. Two patients needed a generator reburial owing to pre-erosion and one an explant and reimplant of a new system owing to infection.

Four patients required an upgrade of their pacemaker system from atrial to dual chamber (table 2).

A pacemaker upgrade was required by four patients overall $(5.8 \%)$. These included one patient in the group aged 70 years or less $(4.2 \%)$, and three in the group aged over 70 years $(6.8 \%)$. Three of the upgrades were carried out in 1995 and 1996.

COST OF IMPLANTATION

Our centre currently charges purchasers $£ 2885$ for a single chamber pacemaker implant and $£ 3844$ for a dual chamber implant, and these are the figures that we used in cost saving calculations. Table 3 shows the costs of pacemaker implantation between 1995 and 1996.

ESTIMATE OF COST SAVINGS BY IMPLANTING

ATRIAL RATHER THAN DUAL CHAMBER PACEMAKERS

To calculate the cost savings we assumed that all patients should have atrial pacemakers, and added to this the cost of upgrading $5.8 \%$ of the pacing systems to dual chamber pacing. In 1995 and 1996, 290 patients would have had atrial pacemakers, with 17 upgrades. The costs accrued by employing this pacing practice are shown in table 4.

By implanting atrial pacemakers in all patients in 1995 and 1996, £206 073 could have been saved. The cost savings thus amount to $£ 103000$ a year.

\section{Discussion}

We are increasingly encouraged to employ the most cost-effective treatment for a given condition. BPEG guidelines are based on best medical practice, and very often most costeffective medical practice. Their recommendation is atrial pacing in patients with sinus node disease. ${ }^{1}$ We have reviewed our pacing practice in patients with sinus node disease over the past seven years and do not appear to be using the most cost-effective pacemaker prescription for these patients, with only a small proportion receiving single chamber atrial pacemakers. The vast majority of our patients (79\% in 1995-96) receive the more expensive dual chamber pacemakers, and we have shown potentially large savings if we were to change our pacemaker practice.

It is also noticeable that more patients currently receive single chamber ventricular pacemakers than single chamber atrial pacemakers. BPEG consider ventricular pacing to be inappropriate in sinus node disease, ${ }^{1}$ and there is good evidence to support atrial rather than ventricular pacing in these patients. Retrospective studies looking at both short term $^{34}$ and long term ${ }^{5}$ follow up have shown a 
higher incidence of the development of atrial fibrillation, chronic heart failure, and thromboembolic events in patients with single chamber ventricular pacemakers, as well as an increased mortality in this group. A prospective study with five year follow up of patients ${ }^{6}$ supports these data, showing an increased likelihood of developing atrial fibrillation and thromboembolism in patients with ventricular pacemakers, though there was no statistical difference in mortality. An ongoing multicentre international prospective study comparing ventricular pacing with synchronous atrioventricular pacing in patients with sinus node disease (the STOP-AF study) ${ }^{12}$ should provide the definitive answer to the question of whether single chamber ventricular pacing is appropriate in such patients.

It would seem that patients with sinus node disease should be treated with atrial pacing. The main concern, however, is that patients with sinus node disease may develop symptomatic atrioventricular block, which would require a revision procedure in those patients with single chamber atrial pacemakers. At implantation there is objective evidence of atrioventricular node disease in approximately $30 \%$ of patients with sinus node disease. However, a review of 28 studies $^{8}$ following up patients with sinus node disease showed the annual incidence of second and third degree atrioventricular block to be between $0 \%$ and $12 \%$, and individual studies have shown that symptomatic high degree atrioventricular block develops in between $4 \%$ and $8.4 \%$ of patients with atrial pacemakers. ${ }^{35} 910$

To overcome the potential problems caused by single chamber ventricular pacing and the risk of the development of atrioventricular block, the ideal pacing mode in patients with sinus node disease would initially appear to be dual chamber pacing. When dual chamber pacing is compared to single chamber ventricular pacing, dual chamber pacing has been shown to be more cost effective. ${ }^{11}$ However, there have been no similar comparisons with single chamber atrial pacing, and dual chamber pacing is not without disadvantages. The implant procedure is more complicated and time consuming, and pulse generator lifespan is generally shorter. More importantly there is the risk of rapid ventricular pacing during atrial tachyarrhythmias and the development of pacemaker mediated re-entry tachycardias. Thus if single chamber atrial pacing is both safe and cost effective in patients with sinus node disease it must be the pacing mode of choice.

In our study we followed up patients retrospectively and found that the percentage of patients with atrial pacemakers who subsequently required an upgrade procedure was small and in keeping with other studies. The vast majority of our patients receive dual chamber pacemakers and significant cost savings could be made by changing our practice, and indeed by following the BPEG recommended pacing prescription.

In this analysis we have used the charge made to the purchasers for these procedures as a measure of cost. While the two are not entirely the same, the charge made for the procedure has been used as a surrogate for the true cost of a procedure in other studies. ${ }^{13}$

Our pacing practice is not entirely in keeping with national pacing practice. In the United Kingdom in 1995-96, of those patients paced for sinus node disease with no evidence of atrioventricular block $10 \%$ received single chamber atrial pacemakers and $44 \%$ dual chamber pacemakers. A change in national pacing practice would not produce such large savings as in our centre, but much money could still be saved.

\section{CONCLUSIONS}

Atrial pacing in sinus node disease is cheaper than dual chamber pacing and is not complicated by the need for a large number of upgrade procedures. The cost benefits of changing pacing practice are significant, and more use should be made of single chamber atrial pacing in patients with sinus node disease.

We are grateful to Nicky Monk for retrieving the patients' case notes and to the technicians who followed up the patients in the pacemaker clinic. We know of no conflicts of interest.

1 Report of a working party of the British Pacing and Electrophysiology Group. Recommendations for pacemaker prescription for symptomatic bradycardia. Br Heart $\mathcal{f}$ 1991;66:185-91.

2 Aggarwal RK, Ray SG, Connelly DT, et al. Trends in pacemaker mode prescription 1984-1994: a single centre study maker mode prescription 1984-1994: a sing

3 Rosenqvist M, Brand J, Schuller H. Atrial versus ventricular pacing in sinus node disease: a treatment comparison study. Am Heart f 1986;111:292-7.

4 Zanini R, Facchinetti A, Gallo G, et al. Morbidity and mortality of patients with sinus node disease: comparative effects of atrial and ventricular pacing. PACE 1990;13: 2076-9.

5 Rosenqvist M, Brand J, Schuller H. Long-term pacing in sinus node disease: effects of stimulation mode on cardiovascular morbidity and mortality. Am Heart 7 1988;116:16-27.

6 Andersen HR, Thuesen L, Bagger JP, et al. Prospective randomised trial of atrial versus ventricular pacing in (1523-8

7 Belen MA, Carisma O, Malano JM, et al. Atrio-ventricular conduction in sick sinus syndrome. PACE 1988;11:163640.

8 Rosenqvist $\mathrm{M}$, Obel WP. Atrial pacing and the risk for AV block: is there a time for change in attitude? $P A C E$ 1989;12:97-101.

9 Swiateka G, Sielski S, Wilczek R, et al. Atrio-ventricular conduction disturbances in patients with sinoatrial node disease and atrial pacing. PACE 1992;15:2074-6.

10 Sutton R, Kenny R-A. The natural history of sick sinus syndrome. PACE 1986;9:1110-14.

11 Sutton R, Bourgeois I. Cost benefit analysis of single and dual chamber pacing for sick sinus syndrome and atrio-ventricular block. An economic sensitivity analysis of the literature. Eur Heart $\mathcal{F}$ 1996;17:574-82.

12 Charles RG, McComb JM. Systematic trial of pacing to prevent atrial fibrillation. Heart 1997;78:224-5.

13 Cardinal DS, Connelly DT, Steinhaus DM, et al. Cost savings with nonthoracotomy implantable cardioverterdefibrillators. Am f Cardiol 1996;78:1255-9. 